\title{
A física e a química no Enem mediadas pelo Diagrama V: uma proposição metodológica
}

\author{
Xavier, L. A. ${ }^{1,4^{*}}$; Scherrer Neto, J. I, M. ${ }^{1}$; Carvalho Filho, J. R. N. ${ }^{1}$; Segatto, B. R. ${ }^{1}$; \\ Rodrigues, C. F. ${ }^{2}$; Xavier, M.G. ${ }^{3}$, Oliveira, B.C. ${ }^{4}$ \\ 1 Programa de Pós-Graduação em Ensino de Física, UFES, Vitória, ES, Brasil. \\ 2 Programa de Pós-Graduação em Educação em Ciências e Matemática, IFES, Vitória, ES, Brasil. \\ 3 Escola Sesc de Ensino Médio, Jacarepaguá, RJ, Brasil. \\ 4 Escola Professora Filomena Quitiba, Piúma, ES, Brasil. \\ *e-mail: lucas.perobas@gmail.com
}

\begin{abstract}
Resumo
O presente artigo relata o uso do Diagrama V, que é a mimetização do método científico para alavancar a qualidade da preparação dos alunos da educação básica no Exame Nacional do Ensino Médio (Enem). O uso dessa nova metodologia ativa se deu por meio de oficinas pedagógicas para que os educandos pudessem obter maior conhecimento e fluência dos elementos constitutivos do diagrama. Em anos anteriores, ao adotar a tecnologia digital, com o uso dos Podcasts na preparação dos alunos, o resultado obtido apontou para a necessidade de acertos. Foram realizadas duas oficinas, a primeira com abordagem sobre o Enem, explorando os competências e habilidades, mercado de trabalho e currículo Lattes e a segunda para orientar no preenchimento do Diagrama V, desempacotando o conhecimento contido nas questões do Enem na área de ciências da natureza. Os materiais utilizados durante o processo foram computadores, data show, celulares dos educandos, sites, folhas A4, entre outros. Os alunos das três séries do ensino médio que utilizaram o diagrama na preparação se sentiram mais confiantes. Portanto, pode-se inferir que a nova metodologia se revela promissora, pois os alunos perceberam a importância da sistematização do conhecimento por meio do método científico.
\end{abstract}

Palavras chave: Enem, Diagrama V, Oficina Pedagógica.

\begin{abstract}
The present article reports the use of Diagram $\mathrm{V}$, which is the mimicry of the scientific method to leverage the quality of the preparation of students from basic education to the National High School Examination (Enem). The use of this new active methodology was done through pedagogical workshops so that the students could obtain more knowledge and fluency of the constituent elements of the diagram. In previous years, when adopting digital technology with the use of podcasts in the preparation of students, the result obtained pointed to the need for some adjustments. Two workshops were held: the first with an Enem approach, exploring competences and skills, labor market and Lattes curriculum, and the second to guide the completion of Diagram V, unpacking the knowledge contained in Enem's science nature. The materials used during the process were computers, data show, cell phones, web sites, A4 sheets, among others. Students in the three high school grades who used the diagram in the preparation felt more confident. Therefore, it can be inferred that the new methodology proves promising, since the students realized the importance of the systematization of knowledge through the scientific method.
\end{abstract}

Keywords: Enem, Diagram V, Pedagogical Workshop. 


\section{Blucher Proceedings \\ X Encontro Científico de Física Aplicada}

\section{Introdução}

Este artigo trata, de uma proposição metodológica de aplicação do Diagrama V na preparação para o Exame Nacional do Ensino Médio (ENEM). O Diagrama $V$ representa uma perspectiva de contornar a problemática educacional de compreensão da sistematização científica por parte dos educandos [1]. Pode ser entendido como um instrumento metodológico norteador tanto do processo de investigação quanto um instrumento de análise e interpretação e avaliação de dados de um estudo [2, 3]. A Figura 1 apresenta os elementos constitutivos deste instrumento.

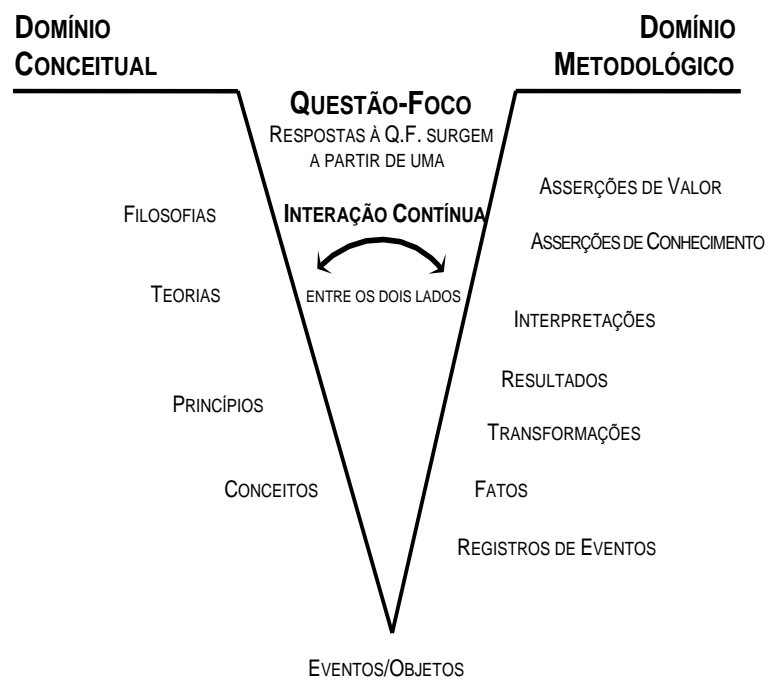

Figura 1: O Diagrama V.

Fonte: Novak \& Gowin (1984, p.3)

E é nessa perspectiva de inovação que se propõe integrar a nova metodologia no ensino de Física e de Química, por meio da utilização do Diagrama $V$ na preparação para o Enem e outros exames, como estratégia didática. O Diagrama V [4]:

[...] é útil porque mostra claramente a produção de conhecimentos como resultante da interação entre dois domínios, um teórico-conceitual e outro metodológico, para responder questões, que são formuladas envolvendo esses dois domínios, a respeito de eventos ou objetos de estudo sobre os quais convergem tais domínios (MOREIRA, 2012, pp. 3-12).

Num século de inovações, introduzir um novo método científico vai de encontro às orientações das Diretrizes Curriculares Nacionais Gerais da Educação Básica [5]: a sobrevivência nesse ambiente requer o aprendizado contínuo ao longo de toda a vida. Esse novo modo de ser requer que o aluno, para além de adquirir determinadas informações e desenvolver habilidades para realizar certas tarefas, deve aprender a aprender, para continuar aprendendo (BRASIL, 2013, p. 163).

O desempenho dos alunos no Enem, disponível na Tabela 1, na Área de Ciência da Natureza da escola, está abaixo de 50\%, o que representa nosso maior problema.

Tabela 1: Desempenho dos alunos no Enem

\begin{tabular}{ccc}
\hline Enem & $\begin{array}{c}\text { Ciências da } \\
\text { Natureza }\end{array}$ & $\begin{array}{r}\text { EEEFM } \\
\text { Filomena } \\
\text { Quitiba }\end{array}$ \\
\hline 2009 & 1000 pontos & 500,7 \\
\hline 2010 & 1000 pontos & 483,6 \\
\hline 2011 & 1000 pontos & 467,1 \\
\hline 2012 & 1000 pontos & 460,7 \\
\hline 2013 & 1000 pontos & 455,1 \\
\hline 2014 & 1000 pontos & 471,5 \\
\hline 2015 & 1000 pontos & 457,9 \\
\hline 2016 & 1000 pontos & 466,4 \\
\hline 2017 & 1000 pontos & 496,8 \\
\hline Fonte: http://educacaoemfoco.sedu.es.gov.br (Adaptação dos autores) & \\
\hline & & \\
\hline & & \\
\hline & & \\
\hline & & \\
\hline
\end{tabular}

Trabalhar com o Diagrama $\mathrm{V}$ representa a busca por novas metodologias investigativas [5]:

atitude de inquietação diante da realidade potencializada pela pesquisa, quando despertada no Ensino Médio, contribui para que o sujeito possa, individual e coletivamente, formular questões de investigação e buscar respostas em um processo autônomo de (re)construção de conhecimentos (BRASIL, 2013, p. 164).

A Figura 2 retrata os índices dos alunos da escola: 15\% atingiram até 450 pontos; entre 450 a 549 pontos, 58\%; entre 550 a 649 o percentual foi $25 \%$; entre 650 a 749 a escola obteve um percentual de $2 \%$ e acima de 750 pontos, não obtiveram percentual. 

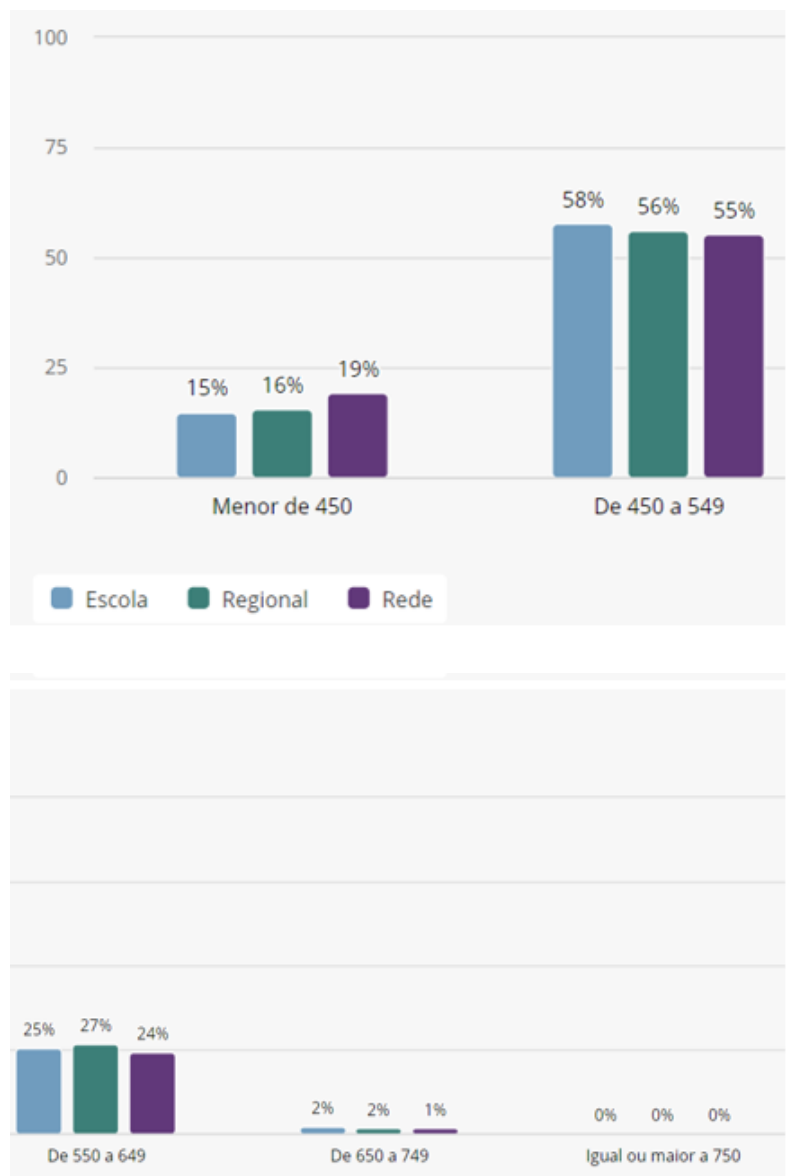

Figura 2: Distribuição de alunos por nível de proficiência (\% de alunos por faixa de nota - 2017).

Fonte: http://educacaoemfoco.sedu.es.gov.br (acesso em 10/04/2019)

O desafio é levar uma grande parcela de alunos para os patamares acima de 650 pontos, ou seja, superar os valores que constam na Tabela 1. Para isso, é necessária uma mudança nas práticas pedagógicas.

$\mathrm{Na}$ perspectiva de inovação foi realizada a integração do Diagrama V no Ensino da Física e da Química na preparação para o ENEM, desenvolvida trimestralmente com alunos das turmas de $1^{\underline{a}}, 2^{\underline{a}}$ e $3^{\underline{a}}$ séries do Ensino Médio Regular da escola da rede estadual Professora Filomena Quítiba localizadas no município de Piúma.

A utilização do Diagrama V com os alunos objetiva obter melhor estratégia de aprendizagem para potencializar a qualidade do ensino. Mas, como motivar o educando na disciplina de Física e de Química? Há várias maneiras de motivá-los, o professor seria uma delas, que se coloque como modelo de pessoa que gosta do que faz [6].

Portanto, como estimular o protagonismo? Quando o aluno trabalha com o diagrama ele percebe a sistematização do conhecimento por meio dos elementos constitutivos na construção de seu conhecimento. O trabalho almeja levar os estudantes do Ensino Médio a se preparar para o Enem, nas disciplinas de Física e Química, utilizando o Diagrama V e estimulando a autoria/ protagonismo na compreensão dos conteúdos das duas disciplinas.

\section{Materiais e métodos}

A metodologia adotada nessa prática baseia-se numa pesquisa de cunho qualitativo com estudo de caso através da produção e coleta de dados [7]. Entretanto, o projeto foi organizado para a aplicação em três etapas nas três séries do Ensino Médio Regular e os dados apresentados neste trabalho correspondem à segunda etapa.

A pesquisa foi desenvolvida na rede pública de ensino, na Escola Estadual de Ensino Fundamental e Médio Professora Filomena Quitiba localizada no município de Piúma/ES. Os sujeitos da pesquisa foram 165 alunos do ensino médio que produziram os diagramas com questões de Física, sendo 6 turmas da segunda série e 4 turmas da terceira série. As questões de Física trabalhada com os educandos foram das provas dos anos de 2009 a 2017. Na disciplina de Química participaram duas turmas da segunda série com um total de 49 alunos e uma turma da terceira série com 23 alunos, que optaram em trabalhar em grupos no uso do diagrama. A proposta de infundir o Diagrama $V$ na escola repercutiu na disciplina de História. A professor que leciona esta disciplina quis experimentar em sua prática pedagógica e envolveu 49 alunos de duas turmas da terceira série explorando as temáticas, "a crise 1929, segunda Guerra Mundial, regimes totalitários e Guerra Fria". A atividade teve uma predominância do sexo feminino com um total de 110 alunas e 55 alunos. A faixa etária dos discentes oscilam entre 16 a 18 anos de idade. 


\section{Blucher Proceedings \\ X Encontro Científico de Física Aplicada}

Em outro artigo Xavier et al [8] relata a realização da primeira etapa com inclusão das tecnologias, uso de Podcasts na preparação dos alunos para o exame na disciplina de Física e Química. Esta etapa contou com uma avaliação diagnóstica para checar os conhecimentos prévios dos educandos. O professor, ao organizar o ensino com foco na aprendizagem significativa, deve considerar os conhecimentos prévios dos alunos, estabelecer o conteúdo a ser ensinado/aprendido assim como organizá-lo de forma lógica e sequencial para favorecer as relações conceituais por parte dos alunos [9]. Foram selecionadas 47 questões das provas anteriores do Enem para os alunos utilizarem nos Podcasts e explorarem os conceitos contemplados em cada questão, assim como, as competências e habilidades, mapa mental do percurso adotado pelo aluno. Foram produzidos mais de 600 Podcasts.

Diante dos resultados obtidos pelos alunos no Enem anterior foi necessária uma adaptação para 2019. A inclusão do Diagrama $V$ no trabalho vem fortalecer a continuidade do trabalho com os alunos. Após duas oficinas ofertadas, os alunos alcançaram maior fluência dos elementos constitutivos do diagrama, a primeira oficina com abordagem sobre o Enem, explorando as competências cognitivas e socioemocionais, mercado de trabalho e a construção do currículo na plataforma Lattes. A segunda oficina teve como propósito orientar no preenchimento do Diagrama V, desempacotando o conhecimento contido nas questões, na disciplina de Física e de Química. Foram utilizados como materiais: computadores, data show, celulares dos educandos, sites, folhas A4, entre outros. Os alunos das três séries do ensino médio que utilizaram o diagrama na preparação se sentiram mais confiantes.

O diagrama como instrumento, teve início a partir do desenvolvimento da atividade proposta, por meio de encontros organizados. As etapas envolveram pesquisa e busca por questões de exames anteriores. Em seguida foi necessário o empenho em desenvolver a proposta escolhida (adequar ao Domínio Conceitual), os alunos foram capazes de reunir o material necessário, questionar o professor sobre possíveis erros e realizar suas próprias conclusões a respeito do resultado que deseja alcançar (Domínio Metodológico). A etapa final foi o compartilhamento com a comunidade escolar, momento em que cada aluno, apresentou os conceitos aprendidos durante todo o processo mediado pela heurística de Gowin.

\section{Resultados e Discussões}

O estudo tratou do uso do Diagrama $V$ no contexto da preparação para o Enem, por meio de oficinas pedagógicas como apoio metodológico na aprendizagem do conteúdo da Física e da Química. A inserção do diagrama permitiu que os educandos aprofundassem seus conhecimentos sobre o instrumento heurístico na sala de aula concernente ao conceito, seu papel e os elementos constitutivos. Dessa forma, o Diagrama $\mathrm{V}$ representa excelente oportunidade para aprender, pois reflete as relações da sistematização do conhecimento.

Foi desenvolvida análise exploratória, com critérios da escala de avaliação [10], que varia conforme o nível de elaboração dos aspectos do Diagrama V. Os alunos cumpriram com os prazos dados para o desenvolvimento da atividade e entrega do instrumento heurístico.

Com relação à Questão-Foco, sua elaboração foi satisfatória, pois bastava fazer uma leitura da questão do Enem e perceber o que ela solicitava do aluno. Entretanto, houve dificuldade em relacioná-la com o lado direito (Domínio teórico) do diagrama. Outra parcela conseguiu relacioná-la aos Conceitos a serem utilizados para respondê-la. Com relação ao elemento Teoria, quase todos os alunos conseguiram relacionar a questão do Enem com o conteúdo do livro didático, ou seja, boa relação com a Questão-Foco, Evento e a teoria da Física/Química do livro do aluno. Para um pequeno número de alunos foi percebido a dificuldade de identificar o Princípio para responder à questão do Enem. O mesmo acontece com o item Conceitos, retratando pouca relação com a Questão-foco e/ou os Eventos. Portanto, no desenvolvimento da atividade desenvolvida embora uma pequena parcela apresentasse dificuldade, perceberam a importância da preparação do trabalho com o método do Diagrama $\mathrm{V}$. 


\section{Blucher Proceedings \\ X Encontro Científico de Física Aplicada}

O item Registros/Dados foi identificado com coerência com o Evento e a Questão-Foco do diagrama. Os elementos do diagrama funcionam de forma normativa para estabelecer os critérios de valor. Uma boa porção de conhecimento deverá incluir todos os elementos do "Vê", ilustrar como é que esses elementos se ligam entre si, e ser coerente, compreensiva e significativa [11].

No item Transformações apresentaram um bom desempenho, conseguindo interligar Registros/Dados em consonância com a Questão-Foco.

Os diagramas dos alunos trazem resultados satisfatórios, derivados dos Registros e Transformações. Realizaram interpretações para obterem as Asserções de Conhecimento e de Asserções de Valor das questões do Enem. $O$ instrumento adotado teve boa aceitação, principalmente para os alunos mais engajados em sua preparação para o exame do Enem. Perceberam o potencial do diagrama como método de pesquisa e de preparação, é necessário bom planejamento, boa técnica, amostra, instrumento de coleta de dados e critérios de análise [2].

O papel da escola precisa passar por reformulação e valorizar a linguagem científica para os alunos. Cada questão do Enem deve ser explorada, seguida de uma Teoria, ou seja, a Fundamentação teórica (quem garante?), Metodologia (como?), Referências (quem garante?). Quanto aos outros elementos do Diagrama V, Princípios e Conceitos, os alunos precisam se aprofundar para obterem mais êxito nas avaliações futuras. No Evento, por exemplo, perceber a Metodologia (como?). Em Registros/Dados/Fatos, visualizar na Metodologia (como?), para chegar aos Resultados. No elemento Transformações enxergar que trata de Metodologia (como?), ou seja, uma análise dos Registros/Dados/Fatos. E, que as Asserções de Conhecimento e Asserções de Valor, são os resultados encontrados ao resolver a questão do Enem.

Os Diagramas Vs dos alunos, preenchidos de forma adequada ao uso do método, posteriormente foram digitalizados e após seleção publicados no site www.wikifisica.com/enem2019/.

$A$ inclusão do Diagrama $V$ como atividade preparatória para o Enem teve o propósito de otimizar o tempo dos alunos, além de representar uma tentativa de exprimir e de valorizar a construção do conhecimento de Física e Química.

\section{Conclusão}

Para efeito de conclusão, a proposição do uso do Diagrama $\mathrm{V}$ foi assertiva para a preparação dos alunos da educação básica no Enem. Por meio dos elementos constitutivos, Evento, formulação da Questão-Foco, identificação dos elementos do Domínio Teórico, da Registros/Dados/Fatos, para serem transformados e obter as Asserções de Conhecimento e Asserções Valor, o recurso potencializa o êxito do educando nas avaliações.

As oficinas realizadas a fim de explorar o método científico e a compreensão do Diagrama $V$, foram fundamentais, por serem de domínios não explorados nas aulas de Física e Química da escola.

Os alunos concordaram com o novo instrumento e querem a continuidade da atividade proposta com o diagrama (www.wikifisica.com/enem2019/). O Diagrama $V$ é facilitador de uma aprendizagem significativa [4]. A contínua interação do Domínio Conceitual com o Domínio Metodológico despertou o interesse, pois perceberam a visualização do método científico. Ajuda a identificar os componentes do conhecimento, clarificar suas relações e apresentá-los de modo claro e visualmente compacto [12].

Os professores de Física e de Química, devido às suas experiências em sala de aula, pontuam as vantagens da atividade preparatória com o Diagrama V, a saber: estímulo aos estudos, interação aluno/aluno e aluno/professor, pesquisa, formação científica, oportunidade de percepção do conhecimento e desenvolvimento dos alunos, entre outras. Ao serem questionados sobre a atividade preparatória, os alunos relataram motivação, aprendizagem e metodologia 
diferente. Se mostrou um caminho a trilhar com os alunos para aprendizagem em Física e Química. O educador do séc. XXI deve ser um profissional da educação que elabora com criatividade os conhecimentos teóricos e críticos sobre a realidade [13]. $\mathrm{O}$ engajamento em atividades escolares abre novos caminhos para conhecer/reaprender os conteúdos das disciplinas [14].

\section{Referências}

[1] GOWIN, D.B. Educating. Ithaca, Cornel University Press, 1981.

[2] FERRACIOLI, L. O “V” Epistemológico como Instrumento Metodológico para 0 Processo de Investigação. Didática Sistêmica, Fundação Universidade Federal do Rio Grande, v.1, p.106-125. 2005.

[3] FERRACIOLI, L. O Diagrama V no Ensino Experimental. 2018, Publicação Interna do ModeLab. Departamento de Física, Universidade Federal do Espírito Santo.

[4] MOREIRA, M. A. Diagramas V e Aprendizagem Significativa. Revista Chilena de Educación Científica, vol. 6, N. 2, pp. 3-12. 2007. Revisado em 2012.

[5] BRASIL. Diretrizes Curriculares Nacionais Gerais da Educação Básica/ Ministério da Educação. Secretária de Educação Básica. Diretoria de Currículos e Educação Integral. - Brasília: MEC, SEB, DICEI, 2013.

[6]. Mapeando a motivação dos alunos. Campinas. Disponível em <http://www.unicamp.br/unicamp/unicamp_hoje/ju/julho 2009/ju435pdf/Pag09.pdf>. Acesso em: abril, 2018.

[7] LÜDKE, Menga e ANDRÉ, Marli E. D. A. Pesquisa em educação: abordagens qualitativas. São Paulo: EPU, 1986.

[8] XAVIER, L. A.; SEGATTO, B. R.; Rodrigues, C. F.; SONDERMANN, D.V.C.; LEITE, Sidnei Quezada Meireles; XAVIER, M.G.; "Integrando tecnologia digital no contexto do ensino de Física e Química na preparação para o Enem", p. 110-115. In: São Paulo: Blucher, 2018. ISSN 2358-2359, DOI 10.5151/ecfa201822

[9] BELMONT, R. S. Contribuições da teoria da aprendizagem significativa para a avaliação educacional. Revista/Meaningful Learning Review V6(3), pp. 79-88, $2016 . \quad$ Disponível em <http://www.if.ufrgs.br/asr/artigos/Artigo_ID91/v6_n3_a2 016.pdf> Acesso em: maio, 2019.

[10] GOWIN, D. B.; ALVAREZ, M. C. The Art Educating with V Diagrams. Cambridge University Press, New York, 2005.

[11] NOVAK, J. D.; GOWIN, D. B. Aprender a Aprender. Lisboa: Plátano Edições Técnicas, 1984.
[12] CAPPELLETTO, E. O Vê de Gowin conectando teoria e experimentação em física geral: questões didáticas, metodológicas e epistemológicas relevantes ao processo. Porto Alegre, 297 p., 2009. Dissertação (Mestrado) - Universidade Federal do Rio Grande do Sul.

[13] ARAÚJO, Paullyanne Leal de YOSHIDA, Sônia Maria Pinheiro Ferro. Professor: Desafios da prática pedagógica na atualidade. Recuperado em 14 de novembro, 2015

http://www.ice.edu.br/TNX/storage/webdisco/2009/11/03/ outros/608f3503025bdeb70200a86b2b89185a.pdf. Acesso em: 17 de maio de 2018.

[14] LUCAS ANTONIO XAVIER and BRENO RODRIGUES SEGATTO. (2018); Gowin Diagram measured by Pedagogical Workshop in the Science Fair context. Int. J. of Adv. Res. 6 (12). 734-740] (ISSN 2320-5407). Disponível em <http://dx.doi.org/10.21474/IJAR01/8193> Acesso em: 12 de abril de 2019. 